\title{
Eventualities and different things: a reply
}

\author{
Claudia Maienborn \\ Humboldt University Berlin
}

\begin{abstract}
"Comments are very welcome!" This basic attitude and the many ways of implementing it contribute immensely to the fascination of engaging in scientific research. I am grateful to Theoretical Linguistics for providing a public platform for this kind of scholarly exchange and I thank all commentators for their thoughtful, stimulating, and often challenging contributions to my target article. My response will address two main issues that are raised by the commentaries. The first issue is shaped by a cluster of questions relating to ontology. The second issue concerns questions of methodology pertaining in particular to the problem of judging data.
\end{abstract}

\section{How much ontology?}

How much ontology do we need when doing semantics? How deep should we delve into ontology when explicating what notions such as 'event' and 'state' actually mean? In Higginbotham's opinion my proposal of drawing an ontological distinction between eventualities (events, processes and $\mathrm{D}$ (avidsonian)-states) on the one hand and the entities expressed by copular constructions and stative verbs (K(imian)-states) on the other ventures out too far. Higginbotham advises caution in this respect: "Whilst insisting that our talk of events, states, and the rest is to be taken seriously, semantics should, in my view, be wary of embracing more in the way of Metaphysics than appears from its own investigations internal to language" (p.7). Most commentators seem to subscribe to this view. From this perspective, and taking into account furthermore considerations of parsimony, it is only natural that the suggestion of a new ontological category is confronted with a fair amount of skepticism. I want to emphasize that I share Higginbotham's concerns, yet my conclusions differ. In particular, I would object to his final judgment: "there is no reason to endow the linguistic/semantic hypothesis of the E-position with an ontological aura involving space and time, or perception" (p.7).

I would first like to emphasize that I am pursuing a cognitive approach to ontology. That is, I understand ontology as the basic conceptual inventory we employ for our (higher) cognitive activities. Under this view, ontology is not concerned with the world itself but rather with the world as conceived and categorized by human beings; see also Dölling's footnote 4 . We should bear in mind that natural language is only one among several sources for gaining insights into the organization of this conceptual category system. Nevertheless language is surely the most profitable source and - bearing in mind Higginbotham's first quote - the one linguists should primarily stick to; see also Bach's (1989) notion of "Natural Language Metaphysics".

I hope that this standpoint on the role of ontology helps clarify some of the misunderstandings in the commentaries. The more general question of whether linguistics/semantics should adopt such a cognitive perspective is of course a matter of dispute. Yet, this cannot be our concern here.

With these introductory remarks in mind, we may turn now to the case of events \& co as used in the Davidsonian framework. Higginbotham takes the core idea to be the following: To appear in Theoretical Linguistics 
"What is proposed, and was emphasized in Davidson's work, is that events are things, and so to be taken up in the same first-order terms as those employed for quantification over, and reference to, the most ordinary objects" (p.7). Again: I agree. Yet I think that we are also obliged to ask what kind of things they are. Does the way we speak about them indicate that ordinary events and ordinary objects - to take these two - are the same kind of thing, and if not, in what respects do they differ? This is the background for my target article, in which I pursued the question of whether there is sufficient linguistic evidence for the (Neo-)Davidsonian assumption that all (verbal) predicates denote eventualities.

My line of argumentation basically involved three steps: (a) I presented a collection of linguistic criteria according to which verbal expressions fall into two groups; (b) this empirical basis was taken as a sufficiently strong linguistic indication of an underlying ontological difference and led to the introduction of K-states besides Davidsonian eventualities; (c) I elaborated the notion of K-states on the basis of further linguistic observations.

The commentators' positions wrt these three points can be classified coarsely as follows: Engelberg basically accepts (a) and (b) but has objections concerning (c). That is, he shares the view that the observed linguistic differences require an ontological solution in terms of assuming a different kind of entity besides eventualities. Engelberg raises a couple of questions showing that my conception of K-states needs to be refined and made more precise in several respects and I am very grateful for his suggestions to this end.

Dölling, Ramchand, and (with some more reservations) Higginbotham basically accept (a) but they reject my conclusion (b). That is, they agree more or less that the observed linguistic differences are real but they do not see the need for assuming a new kind of entity. Rather, they suggest, the data call for a more liberal definition of eventualities than the one I argued for. Under this view, copular constructions and stative verbs denote a subtype of eventualities.

Finally, Rothstein casts doubts already on (a). That is, she rejects my claim that there is a grammatically relevant split between the two groups of verbal expressions both by presenting some counterevidence and by advocating a pragmatic explanation for some of the observed "anomalies". It is worth pointing out though that Rothstein's view on eventualities is in accordance in relevant parts with mine.

This survey of the different positions makes it clear that the Davidsonian notion of event(ualitie)s, which has become such a familiar, "all-purpose" linguistic instrument over the past decades, is anything but self-explanatory. To draw attention to some of the incongruities lurking in the literature was one of the aims of my article. One of the crucial points at issue is whether we adopt a narrow or a wide definition of eventualities.

\section{A narrow or wide definition of eventualities?}

In (1) I repeat the definition of eventualities that I advocated in my target article (p. xx).

\section{Davidsonian notion of eventualities:}

Eventualities are particular spatiotemporal entities with functionally integrated participants.

Under this view, eventualities are expected, among other things, to have a location in space, and natural language expressions denoting eventualities should therefore combine with locative modifiers. As noted above, Higginbotham, Ramchand and Dölling take the definition in (1) to be 
too narrow. In particular, they reject the assumption of eventualities having an inherent spatial dimension; cf., e.g., the alternative definition offered by Ramchand (p.9), which I repeat in (2).

(2) Eventualities are abstract entities with constitutive participants and with a constitutive relation to the temporal dimension.

To illustrate one line of reasoning, I quote one of Dölling's examples (his (1a) and (2a)); cf. Ramchand (p.5) for similar remarks. (Note that both sentences in (3) are "bad".)
a. Hans wurde (gerade) in Italien 30 Jahre alt.
Hans became (at the moment) in Italy 30 years old.
b. Hans war (gerade) in Italien 30 Jahre alt.
Hans was (at the moment) in Italy 30 years old.

Dölling observes that the verbal expression 'to become 30 years old' in (3a) is obviously eventive and should therefore - on my definition in (1) - combine with a locative modifier. Yet, this is not possible. So my account seems to make the wrong predictions. It excludes (3b) as ungrammatical but tolerates (3a), which, according to Dölling (p.2), is equally deviant. Dölling takes (3a) and similar data as evidence that eventualities may lack a spatial dimension. Hence, definition (1) should be dismissed in favour of a wider definition of eventualities along the lines of (2). Cases like 'becoming 30 years old' and 'being 30 years old' would then belong to a subtype of eventualities that have no location in space, which would explain why $(3 \mathrm{a}, \mathrm{b})$ are odd.

In order to assess this argument let us first see what happens if we vary the predicate somewhat as in (4).
a. Hans wurde (gerade) in der Küche ohnmächtig /wütend/blass/seltsam... Hans became (at the moment) in the kitchen unconscious/angry /pale /strange...
b. * Hans war (gerade) in der Küche ohnmächtig/wütend/blass/seltsam... Hans was (at the moment) in the kitchen unconscious/angry /pale/strange...

The stative variant (4b) remains "bad" (in my terms: ungrammatical), but the eventive variant (4a) is perfectly fine now, which is what my account would predict. So, what is responsible for the deviance of (3a)? In my view, this is an instance of a conceptual mismatch. If we choose a more appropriate locative modifier, which fits better with the event, as in (3'a), the sentence recovers its grammaticality again, while the stative variant $\left(3^{\prime} b\right)$ still is ungrammatical.

(3') a. Hans wurde (gestern) im Kreise seiner Familie 90 Jahre alt. Hans became (yesterday) in.the circle of his family 90 years old.

b. * Hans war (gestern) im Kreise seiner Familie 90 Jahre alt. Hans was (yesterday) in.the circle of his family 90 years old.

Whatever the exact conditions for such conceptual matches and mismatches may be, they do not form part of the grammar. Thus, I would maintain that the b-sentences above are ruled out on grammatical grounds (due to the absence of an eventuality argument), whereas all a-sentences are grammatically well-formed. This is as far as our linguistic knowledge takes us - which does not preclude that cases like (3a) will be judged as more or less anomalous on the basis of world knowledge. 
Drawing the borderline between linguistic and extra-linguistic knowledge is an extremely intricate and highly controversial issue indeed, and every single case needs careful consideration. Therefore, I believe, we should all the more look for clear linguistic diagnostics and apply them with caution. To give an illustration, take the following quote from Ramchand (p.5): "given that complex dynamic events like 'deciding' are sometimes difficult to perceive, and that copular predications like 'being on the table' are always easy to perceive, means that the distinction also cannot be related to some ontological difference in perceptibility or 'locatability' in real space and time."

Ramchand is right; 'deciding' is definitely not one of the "harmless" events like 'Jones buttering a toast' or 'Brutus stabbing Caesar' that always come to the Davidsonian semanticist's mind first. And it may well be that cases like 'deciding' or 'contemplating' requires a further distinction between ordinary, concrete eventualities and somehow non-concrete, ("abstract") eventualities, in the same vein as there may be concrete and abstract objects, concrete and abstract paths, etc. I do not want to dispute this, but note that the linguistic diagnostics show clear results even for these less easily accessible eventualities. Take, e.g., 'contemplating'. As (5a) shows, the process verb can be combined with a locative modifier; while the stative variant in $(5 b)$ is ungrammatical in this combination.
a. Um Mitternacht hatte Anna im Park (über ihre Zukunft) nachgedacht.
At midnight had Anna it.the park (her future) contemplated.
b. * Um Mitternacht war Anna im Park nachdenklich.
At midnight was Anna in.the park contemplative.

Furthermore, the "a little bit"-diagnostic, which I introduced in section 4.4 of the target article, yields equally clear results:
a. Gestern hat Anna ein bisschen nachgedacht.
Yesterday has Anna a little bit contemplated.
b. Gestern war Anna ein bisschen nachdenklich.
degree and eventive reading
only degree reading

While (6a) has both a degree reading and an eventive reading; (6b) only displays the degree reading. That is, sentence (6b) cannot express that yesterday Anna was contemplative for a short while. Obviously, such a reading would make perfect sense and thus cannot be discarded as a conceptual mismatch. Rather, I would maintain, it is the grammar that discards the eventive reading in (6b) (given that the modifier selects (homogeneous) eventuality arguments; see the discussion in the target article).

Finally, these results are further confirmed by the perception reports in (7). As I readily admit in consideration of the questions that arose in the commentaries, there appear to be many other factors involved here that still have to be disentangled in order to make the perception verb test a manageable and solid eventuality diagnostic.
a. Gestern habe ich Anna nachdenken gesehen.
Yesterday have I Anna contemplate seen.
b. * Gestern habe ich Anna nachdenklich sein gesehen. Yesterday have I Anna contemplative be seen. 
What the sentences (5) and (6), and with some caveat (7), show is the following. While the actual scenes they describe are similarly inaccessible - they could be even identical - the linguistic diagnostics reveal a clear difference hinting at two different conceptualizations. These conceptualizations contrast sharply wrt the presence or absence of a spatial dimension.

On the other hand, replacing a more difficult state to grasp like 'being contemplative' by an easily perceptible and in this sense concrete state like Ramchand's 'being on the table' or 'being wet' does not have any impact on the outcome of our linguistic diagnostics:
a. * Das Kleid war (gerade) auf der Wäscheleine nass.
The dress was (at the moment) on the clothesline wet.
b. Das Kleid war ein bisschen nass.
only degree reading

The combination with an (eventuality-related) locative modifier is ruled out in (8a), although it would make sense, i.e., there is no conceptual mismatch at work; see the discussion of (23)-(25) in the target article. And (8b) lacks the eventive reading of ein bisschen.

I do not see how data like (5)-(8) could be accounted for adequately in a more liberal framework based on a broader definition of eventualities along the lines of (2) as envisaged by Ramchand and Dölling. The basic idea would be to conceive of D-states and K-states as different subtypes of eventualities. Dölling (p.3) notes: "States would divide, then, in analogy to events into two kinds as subtypes of the category of eventualities - spatial states, on the one hand, and non-spatial states, on the other hand." On this account, could there be any independent motivation for classifying, e.g., 'being wet' as a non-spatial state? And why should ein bisschen on its eventive reading accept any kind of process arguments but only non-spatial state arguments? Furthermore, would locative predications like to be on the table, which assign a location to the subject referent, also denote non-spatial states then (given that they behave like other K-state expressions wrt the relevant linguistic tests)?

To my mind, the idea of postulating two kinds of states as subtypes of the category of eventualities depending on whether they can be located in space or not, seems rather ad hoc. A subdivision of eventualities into events (accomplishments and achievements), processes, and states in the spirit of Vendler (1967) is based on temporal/aspectual criteria. Why should nondynamic, homogeneous eventualities (i.e. states) divide further into spatial and non-spatial subtypes? And why should expressions referring to non-spatial states moreover exclude modification of manner adverbs or eventive ein bisschen? This would have to be stipulated.

In the end, assuming K-states not as a subtype of eventualities but as an alternative entity might be not as hazardous from an ontological point of view as it appears at first. In some respects, e.g. reference, inherence of a temporal dimension, K-states are as ordinary things as eventualities are. It is worth pointing out in this context that Dölling's considerations concerning the inferential behavior of K-states lead to the conclusion that K-state-based approaches and eventuality-based approaches basically have the same merits and problems in handling the relevant entailment patterns; see Dölling's footnotes 9 and 10. In lacking an inherent spatial dimension K-states are more abstract entities than eventualities.

\section{Judging data}

The issue of evaluating the empirical data properly already came up in the above discussion of the sentences in (3) vs. (3'). When it comes to specify the reasons for a sentence being "bad", 
opinions may differ considerably. A sentence's oddness might be explained in terms of ungrammaticality, conceptual ill-formedness, pragmatic anomaly, etc. This point is picked up by Rothstein's commentary. Rothstein argues that the empirical data that I present for my claim that there is a clear grammatical distinction between eventuality expressions and $\mathrm{K}$-state expressions are not solid enough. The observed differences do not justify then the postulation of different logical structures but might rather be conducive to a pragmatic explanation.

Since it would go beyond the scope of this reply to look at each of Rothstein's and the other commentators' counter-examples carefully, I will pick out only two cases which I find particularly telling for the issue of judging data.

Rothstein presents a number of examples suggesting that copular constructions, contrary to what I claim, do combine with (eventuality-related) locative modifiers. One class of examples are her sentences (11), which I repeat in (9).

a. John is happy in the swimming pool.

b. John is lazy in Paris.

According to Rothstein, a sentence like (9a) should be analyzed as expressing that there is a state of John being happy and this state is located in the swimming pool. This would indeed disprove my claim concerning the incompatibility of locative modifiers with copular constructions. Yet, I must insist that the structure behind sentences like (9) is quite different than that envisioned by Rothstein. Furthermore, it is the syntactic structure that is different here. Rothstein's account presupposes a syntactic analysis according to which the adjective figures as the main predicate and the locative PP is a VP-modifier. But there is an alternative syntactic analysis to these sentences according to which it is the locative that builds the main predicate and the adjective is a depictive secondary predicate. Under this syntactic analysis (and without commitment to any particular theory of depictives) sentence (9a) would express that there is a state of John being in the swimming pool, and this state is temporally included in an accompanying state of John being happy. Such an analysis of data like (9) would leave my claim concerning locative modifiers unaffected, simply because no locative modification is involved. In order to account for (9) my analysis would only need to be extended to allow K-state arguments to not only be introduced into primary predications (via the copula) but also into (depictive) secondary predications; see, e.g., Dölling's (p.6f) suggestions concerning the underlying logical structure.

This might be the right place to add a short remark on the source of the K-state argument. This issue is discussed most explicitly by Engelberg, who opts for shifting the source of the state argument from the copula to the main predicate; see Engelberg's proposal in (19). Higginbotham and Ramchand hold similar views. As Engelberg (p.9) rightly observes, my main concern was with the nature of the state argument rather than with its source. Since up to now I haven't seen a convincing solution for the problem of how state arguments could be bound outside the realms of primary and secondary predication, I prefer to stick to the more parsimonious assumption. (Ramchand's (p.7) objection that my "nominal-style" representation of adjectives obscures the difference between adjectives and nouns does not apply. Nouns and adjectives do not necessarily differ in arity but in the status of their argument. The noun's argument is assigned the status of a referential argument, while the adjective's argument is non-referential; see e.g. Bierwisch (1997).)

Let us turn back to the issue of (9). So far we have seen that there are two possible syntactic structures for (9). The locative PP could either be a VP-modifier or the sentence's main predicate. So, is this a case of structural ambiguity, or is only one analysis correct? Let us have a look at German here because word order may help us differentiate the two analyses. In the 
German counterparts to (9) the main predicate is in sentence final position and a VP-modifier or depictive appears preverbally. The two structural options are given in (10). Only one of them, (10b), turns out to be grammatical. (The temporal modifier is added in order to inhibit framesetting interferences; see section 4.2 of the target article.)
a. * John ist (gerade) im Schwimmbad fröhlich.
loc PP: VP-modifier John is (at the moment) in.the swimmingpool happy.
b. John ist (gerade) fröhlich im Schwimmbad. John is (at the moment) happy in.the swimmingpool.
loc PP: main predicate

The German data show that there is in fact only one possible structural analysis for the constructions at issue. The adjective must precede the locative PP, which means that we are dealing with a locative main predicate in combination with an adjectival secondary predicate. This suggests that the English counterpart (9) is structurally unambiguous, too. I conclude then that sentences like (9) do not provide counter-evidence to my claim concerning the incompatibility of locative modifiers with copular constructions.

The second kind of counter-example from Rothstein I want to discuss is sentence (11) (her (13)), which serves Rothstein as an illustration of her pragmatic approach to the anomaly of event modifiers in copula sentences.

(11) John is dangerous with a hammer.

In Rothstein's view, copular constructions and statives denote somewhat poor eventualities with little scope for variance. This is why manner adverbials, instrumentals and the like show up so rarely: although grammatically well-formed they simply make no sense. As Rothstein notes on $p$. $\mathrm{xx}$, "many of the non-locative modifiers that we allow demand properties which are not normally associated with states, for example instrumentals are associated with agentivity. When a copula construction can be interpreted with an agentive subject, an instrumental is acceptable."

So let us take a closer look at (11). I assume that Rothstein's account of (11) basically goes like this. The copula be introduces a referential argument for a semantically underspecified eventuality, which is compatible with any of Vendler's event types. Since instrumentals select for activity arguments and given furthermore that the subject John is a potential agent, be's eventuality argument is narrowed down to activities. This yields the following interpretation for sentence (11): There is an activity of John being dangerous and a hammer is being used as an instrument in this activity; see Rothstein (1999) for details.

First I should say that I am not sure whether this is indeed the right interpretation for (11). At least the German counterpart (12) does not have this reading but only has a conditional interpretation (pertaining to an analysis of the instrumental as a frame-setting modifier), saying that if John is in possession of a hammer then he is dangerous.

John ist mit einem Hammer gefährlich.

John is with a hammer dangerous.

One piece of additional support for the assumption that the instrumental is in fact a frame-setting modifier here may be gained by looking at negation; cf. the discussion in section 4.2 of the target article. The sentential negation of (12) yields (13a) with the instrumental being outside the scope of negation. The reverse order (13b) expresses only constituent negation of the instrumental. 
a. John ist mit einem Hammer nicht gefährlich. John is with a hammer not dangerous.

b. John ist nicht mit einem Hammer gefährlich (... sondern mit einem Messer). John is not with a hammer dangerous (... but with a knife).

So, at least the German counterparts of (11) cannot serve as illustrations for an activity interpretation of copula sentences. Nevertheless I agree with Rothstein that such interpretations may show up. In my view, a better candidate would be (14).

John ist mit einem Hammer auf dem Dach.

John is with a hammer on the roof.

This sentence may in fact have an activity interpretation according to which there is an eventuality of John doing something with a hammer, and this activity is located on the roof. The crucial question is: How do we reach at this interpretation? While Rothstein would take cases like (14) to be an instance of semantic underspecification, I assume that they involve a noncompositional operation of event coercion. More specifically, my explanation goes like this; see Maienborn (2003a, b) for details. Sentences like (14) are strictly speaking ungrammatical because the copular construction does not meet the sortal requirements of the instrumental. Nevertheless, given our ability to associate with states like 'being on the roof' characteristic activities, like, e.g., 'repairing the roof', such sentences may be "rescued" by interpolating a suitable eventuality argument. Once introduced, this argument may serve as the target for the adverbial's meaning contribution. That is, under certain pragmatic conditions the sortal clash between an event modifier and a K-state expression may be resolved via a non-compositional operation by which an appropriate eventuality argument is inserted into the logical structure; see e.g. Egg (2001) for a formal treatment of coercion. (Let me note in passing that I consider coercion to be a phenomenon located at the interface between the linguistic and the conceptual system, whereas Higginbotham seems to assume that - if existent at all - coercion should be seen as part of the linguistic system, see his footnote 4.)

If we compare Rothstein's approach to sentences like (14) with mine it is easy to see that they have a considerable amount in common. The main point of divergence is whether assuming the activity argument is a regular part of the interpretation process in terms of a resolved semantic underspecification, or whether it is part of an irregular rescue-operation for a literally ungrammatical sentence.

In view of all the factors involved here, many of them still remaining rather mysterious, we are probably not in the position to decide this issue yet. So, I just want to give one piece of data that seems to be problematic for the underspecification account. We would expect on this account that a sentence like (14) is a regular activity sentence. Thus, it should behave like other activity sentences in the relevant respects. One suitable diagnostic for testing this prediction is anaphoric reference with geschehen ('to happen'); see the discussion of (11)-(13) in the target article. While event and process (including activity) arguments can be resumed with the help of this proform, state arguments cannot. Now, as (15) shows, our sample sentence does not pass this test. A true activity expression is given in (16) for comparison.

John war mit einem Hammer auf dem Dach. John was with a hammer on the roof.
* Das geschah während ... This happened while ... 
(16) John arbeitete mit einem Hammer auf dem Dach.

Das geschah während ...

John worked with a hammer on the roof.

This happened while ...

Despite its activity (re-)interpretation, sentence (14) still behaves like a state sentence. This is unexpected under an underspecification account. Thus (15) seems to fit better with my coercion account, according to which the integration of the instrumental is only due to a local rescue operation.

Needless to say that the issue is far from being settled. I therefore repeat: Comments are very welcome!

\section{References}

BACH, Emmon (1989). Informal Lectures on Formal Semantics. New York: State University of New York Press

BIERWISCH, Manfred (1997). Lexical Information from a Minimalist Point of View. In: C. WILDER, H.-M. GÄRTNER \& M. BIERWISCH (eds.). The Role of Economy Principles in Linguistic Theory (pp. 227-266). Berlin: Akademie-Verlag.

EGG, Markus (2001). Beginning novels and finishing hamburgers - Remarks on the semantics of to begin. Linguistische Arbeitsberichte, 76, pp. 295-319

MAIENBORN, Claudia (2003a). Die logische Form von Kopula-Sätzen (studia grammatica 56). Berlin: Akademie-Verlag

MAIENBORN, Claudia (2003b). On Davidsonian and Kimian states. To appear in: I. COMOROVSKI \& K. v. HEUSINGER (eds.). Existence: Semantics and Syntax. Dordrecht: Kluwer

ROTHSTEIN, Susan (1999). Fine-grained Structure in the Eventuality Domain: The Semantics of Predicative Adjective Phrases and Be. Natural Language Semantics, 7, pp. 347-420

VENDLER, Zeno (1967). Linguistics in Philosopy. Ithaca, New York: Cornell University Press 